Open Access

\title{
The recent trend of ethnic intermarriage in China: an analysis based on the census data
}

\author{
Zhixiang Jian(10
}

\author{
Correspondence: jzx6812@sina.com \\ Minzu University of China, Beijing, \\ China
}

\begin{abstract}
Interethnic marriage is a key field in ethnic relations study. A high level of interethnic marriage only occurs in a multiethnic society in which the political system, economic structure, laws, and cultural environment allow young people with different ethnic backgrounds to mingle with each other. This is why the interethnic marriage rate can be used to measure the degree of interactions among different ethnic groups. It is the most reliable indicator for a trend of long-term ethnic relations. Due to the lack of relevant data in official statistics, there are limited studies focusing on interethnic marriage at the macro level. Based on the 1990, 2000, and 2010 census data and the special volume on ethnicity edited by the State Ethnic Affairs Commission, this paper attempts to determine the basic trend of interethnic marriages in China over the past three decades. It discusses some basic characteristics of interethnic marriages among different ethnic groups. How to strengthen national unity, ethnic solidarity, and improve the relationships among different ethnic groups are major challenges faced by China in the twenty-first century. Studying the interethnic marriage from sociological and demographic approaches may help us understand the basic trend of interethnic integration in today's China.
\end{abstract}

Keywords: Interethnic marriage, Ethnic differences, Regional differences

Since the 1950s, the Chinese government has officially recognized 55 ethnic minorities and defined the ethnic identity of each citizen. In addition, the government has set up five autonomous regions, 30 autonomous prefectures, and 120 autonomous counties (banners) for ethnic minorities. Minority autonomous areas account for $64 \%$ of the country's land area. The sixth national census (2010) data shows that the population of China's 55 ethnic minorities totals 112 million, accounting for $8.49 \%$ of the total population. The size and characteristics of geographical distribution of the ethnic minority population ${ }^{1}$ demonstrate that ethnic relations have a very significant impact on China's national unity, social stability, economic development, cultural prosperity, and international relations. Studying the population change of China's various ethnic groups from a demographic perspective is one of the most important ways to examine the status quo of China's ethnic relations and development trend.

Sociologists consider ethnicity studies an important research field. One of the core topics in the sociological studies of ethnic relations is interethnic marriage within the country. Due to the lack of interethnic marriage data based on official statistics and investigations conducted by scholars, the macro quantitative study of internal interethnic marriage in China has been relatively limited. This paper analyzes data from China's

(c) The Author(s). 2017 Open Access This article is distributed under the terms of the Creative Commons Attribution 4.0 International License (http://creativecommons.org/licenses/by/4.0/), which permits unrestricted use, distribution, and reproduction in any medium, provided you give appropriate credit to the original author(s) and the source, provide a link to the Creative Commons license, and indicate if changes were made. 
three recent population censuses, in particular, the intermarriage data jointly presented by the National Bureau of Statistics and the State Ethnic Affairs Commission, in order to understand the evolving trend of ethnic intermarriages over the past 20 years, as well as the demographic characteristics of various ethnic groups in ethnic intermarriage.

\section{Literature review of interethnic marriage studies}

Due to differences in regional development and the migration of human society, most countries in today's world are multiethnic. Their citizens include members of various minority groups that differ from the dominant group in physical characteristics, consanguinity, language, religion, cultural practices, social and political processes, and so on. How to establish a legal and institutional relationship between mainstream and ethnic minorities and how to examine the interaction mechanisms of interethnic communication and the evolving trend of ethnic relations are always major concerns of governments and academia in these multiethnic countries.

\section{Ethnic intermarriage research in Western sociology}

Ethnic intermarriage is closely related to the degree of difference between ethnic groups and to social, economic, cultural, political, and other factors that caused such differences. In addition, ethnic intermarriage directly affects changes in group boundaries; thus, the trend of ethnic intermarriage also has an important influence on domestic social integration. Therefore ethnic intermarriage is considered one of the most important research topics in sociological ethnic studies. Max Weber believed that "in all those who have a well developed "ethnic" awareness of the population, the existence or lack of ethnic intermarriage is usually the consequence of racial attraction or segregation" (Weber 1978: 385). George E. Simpson and Milton Yinger regard the ethnic intermarriage rate as the most sensitive index of measuring ethnic integration and "social distance" of all races and ethnic groups in the USA in determining the degree and trend of ethnic groups' integration (Simpson and Milton Yinger 1985: 296). In Milton Gordon's Assimilation in American Life, he proposes seven variables to research and measure ethnic groups' integration, of which the most important is intermarriage. He believes that "intermarriage is the inevitable accompaniment of (ethnic) social organization's integration" (Gordon 1964: 80). Enloe points out that intermarriage is the baseline of ethnicity. He believes that ethnicity will change or disappear as soon as a large scale of intermarriage emerges (Enloe 1996: 199). These research findings suggest that only when widespread social interaction is maintained in majority members of the two ethnic groups, as well as all aspects of social life gradually becoming consistent or highly harmonious between the two groups, will a large number of intermarriages arise. The white descendants of immigrants from various European countries have been able to form a mutually recognized "white American population" largely based on a high rate of intermarriage (Alba 1990: 167).

Western scholars have conducted much research on American ethnic intermarriage and summarized some interesting variables. For example, Thernstrom and Thernstrom use the "Priority List of Ethnic in Intermarriage" in the survey to analyze racial/ethnic preference in intermarriages (2002: 1); Simpson and Milton Yinger (1985) analyze the sex ratios of intermarried couples and the regional differences in intermarriage; Goldscheider, Frances K., and Goldscheider, Calvin (1989) compare the religious 
backgrounds of intermarried couples; Feagin Joe and Feagin Clairece (1996) analyze intergenerational differences in ethnic intermarriage; Blau (1991) explores the influence of the relative size of the population on ethnic intermarriage; and Xie and Goyette (1997) discuss the influences of language usage on ethnic intermarriage. The research topics and analysis perspectives in the above literature provide many insights into a better understanding of ethnic relations in sociological studies and enlighten the sociological research on ethnic intermarriage in China.

Western scholars also pay close attention to ethnic intermarriages in their studies of China's ethnic relations. China's Forty Millions: Minority Nationalities and National Integration in the People's Republic of China, the earliest published monograph in the USA on China's ethnic minorities, recognizes that Tibetan-Han intermarriage has a long history. However, it expressed concern that the intermarriages that arose between Han soldiers and Tibetan women after the People's Liberation Army went into Tibet could influence the sex ratio of the local population and lead to a conflict (Dreyer 1976). Some scholars who study the history of Chinese ethnic relations believe that Chinese empires in the Central Plains often encouraged intermarriage as an official means of "enlightening" the barbarians (Dikötter 1992: 57). Other scholars have pointed out that ethnic intermarriage and cultural exchanges contributed to the weakening of ethnic boundaries in many countries. However, this natural process is objectively impeded by the "ethnic minority identity" registration system that the contemporary Chinese government provides for children born from intermarriage (Mullaney 2011). These studies point out that intermarriage in China has a long history. In order to understand the intermarriage phenomenon in contemporary China, the government's policy direction and identity system are key factors that cannot be ignored.

\section{Intermarriage research by Chinese scholars}

Chinese historical documents record a large amount of intermarriage information of various dynasties and royal families. Historian Wang Tongling was the first to systematize these historical materials. He compiled the related documents of ethnic intermarriages, such as minority women serving in the royal palace, and the intermarriages of princess and females of royal families, believing that intermarriage was one of the main methods for dominant groups to assimilate other ethnic groups (Wang 1934).

In the 1950s, the Chinese government called scholars together to launch a large-scale social and historical investigation into ethnic minority areas. The final reports present substantial descriptions of ethnic intermarriage in the communities but lack quantitative analysis, as well as comparative research and discussions of the intermarriage system (Ma et al. 2001). One well-known study in the research on ethnic intermarriage conducted after 1949 was Marriage and Family of Chinese Ethnic Minorities edited by Yan Ruxian (1986). This work provides basic information for understanding ethnic minorities' marriage patterns. Other Chinese scholars subsequently published monographs on ethnic intermarriages, mainly on intermarriage cases recorded in the literature (Chen 1993).

Judging from CNKI's relevant academic literature and data, the recent academic research on contemporary ethnic intermarriage mainly involve case studies that use the ethnographic and anthropological approach to intermarriages of one region, or one or several minority groups. This approach is individualized, dispersed, and specific and 
lacks general and comparative studies on marriage patterns. Ma and Pan (1988) analyzed the structural features of Han-Mongolian intermarriages in the agricultural and pastoral areas of Chifeng in Inner Mongolia. Their study was the first to use the sociological sampling questionnaire survey method in China's intermarriage research. They found that Mongolian and Han villagers had different "marry-up models" based on the respective traditional economic activities of each group. This sociological study sets a precedent by using quantitative analysis and model analysis on Chinese ethnic intermarriages. Subsequently, Chinese scholars' study of intermarriages by utilizing sociological methods gradually increased (Ma 1996; Wang 1999; Jian 2004; Liang 2008; Li 2008, 2012; Gao and Zhang 2014; Zhao and Xu 2014).

Population census data is an important source for analyzing a country or region's ethnic intermarriage pattern at the macro level. Similar to the analysis in "Priority List of Ethnic in Intermarriage" (Thernstrom and Thernstrom 2002: 1), Li Xiaoxia analyzes the "intermarriage circle" of Chinese ethnic minorities by using 2000 census data, pointing out that most ethnic minorities have high rates of intermarriage with Han and form a Han-centered ethnic intermarriage model (Li 2004a, b). "Marriage Age, Number of Children Ever Born, and the Ethnic Identification of Children of Inter-ethnic Marriage: Evidence from China population census in 2000," written by Guo and Li (2008), is a classic study using population census data to analyze the demographic characteristics of ethnic intermarriages. It concludes that ethnic intermarriage can significantly delay marriage age and reduce the number of children. The children of an ethnic intermarriage tend to be identified as ethnic-minority individuals. Liu and Zhang (2015) compare the Fifth Census and the Sixth Census data to analyze the status and trend of minority ethnic intermarriage. They point out that a prevalent tendency of gender selection and an obvious marry-up model exist in China's ethnic intermarriages.

In Ma Rong's "Ethnic minorities' intermarriage in China" (2001), based on the variables affecting intermarriage discussed by Western scholars, the author attempts to create a theoretical model of ethnic intermarriage. By proposing an analytical and theoretical framework, the model makes efforts to cover various factors that could affect ethnic intermarriage and discusses the path of these factors (see Fig. 1). It is a useful attempt to summarize varied research in a comprehensive thematic macro model.

Sociologists study the ethnic intermarriage rate to measure the intensity and nature of ethnic relations and regard the rate as the most reliable and sensitive indicator for measuring interethnic relations and their changes in a country. Through changes in the

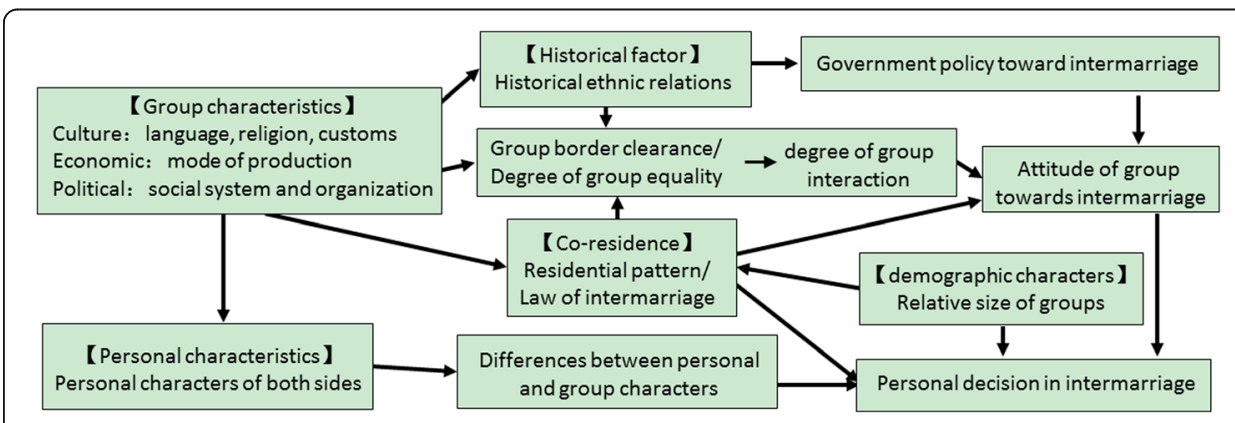

Fig. 1 Factors affecting personal preference in intermarriages. Source: Ma Rong $(2001,164)$ 
format of intermarriage and the various factors that cause the change, the status and trends of ethnic relations can be recognized and predicted.

From the existing research literature and theoretical models of intermarriage, we can deduce that four basic conditions are needed for a multiethnic society to have a high intermarriage rate: (1) the ethnic group's culture integration has reached a high degree, with no language obstacles and no religious conflicts, or at least tolerance toward other religions; (2) ethnic group members have adequate opportunities to contact and love each other; (3) there is no overall gender bias or ethnic discrimination among groups; (4) families and communities do not oppose intermarriage, or even view it positively. Only in societies where the above social conditions and culture atmosphere appear can large-scale ethnic intermarriage exist (Ma 2004).

The above research works are all helpful in analyzing community surveys or questionnaire data. However, in the face of China's macro level population census data, variables that can be used as quantitative comparison and analyzing factors are usually limited to the ethnic groups' population scale, the social-structure characteristics of the population, ethnic population settlement levels, linguistic differences between ethnic groups, and so on.

\section{Statistical data on intermarriages in China}

Because sociology as a discipline was suspended in China from the 1950s to the 1970s and the professional sociological studies of ethnic relations recovered quite late, the research findings are relatively limited. The national and regional socioeconomic statistical yearbooks published by Chinese government were based only on administrative divisions (province, prefecture, county), but did not use "ethnic groups" as statistical units. As a result, it is impossible to make a comparative analysis of ethnic groups by using annual statistical data. The 1953 and 1964 censuses only provided information about the population size and geographic distribution of all ethnic groups, and the 1982 census only included ethnic-group information on age, gender, marriage status, education, industry, and occupation.

Only the last three censuses since 1990 provide data on ethnic intermarriage, which is the only source for Chinese scholars to obtain nationwide data on ethnicity and intermarriages. The current scarcity of data sources has largely limited researchers' study of China's ethnic intermarriage at the macro level and to grasp its trend. On a particular note, the statistical intermarriage data is not consistent in the 1990, 2000, and 2010 censuses. There are two types of statistics.

The first type of data divides all family households into three categories-all members belong to ethnic minorities, members are a mixture of a minority group and Han, all members are Han-and counts the number of households and the various subordinate people in each household in each county, province, and all over the country. The second type of data divides all family households into four categories-single ethnic household, members of the household are from two ethnic groups, household members are from three ethnic groups, and household members are from four or more ethnic groups-and calculates the total number of households and the proportion in each category. The first type of data is provided by the 1990 census in a print edition and the 2000 census in a digital edition; the second type of data is provided by the 2000 and 2010 censuses, both in print editions. These two types of published data sets provide 
limited information for in-depth analysis since in the first type of data the category "all ethnic minority households" does not differentiate between "same ethnic minority households" (marriage within the same ethnic minority group) and " households of intermarriage among different ethnic minorities." Thus, the 55 ethnic minorities can only be viewed as a whole when analyzing their intermarriages with the Han majority. While the second type of data displays the number of ethnic minorities among household members, it neither displays the intermarriage situation between Han and other ethnic groups nor to which particular ethnic group intermarried members belong.

Fortunately, the "Chinese Ethnic Population Data in the 2000 Census" and the "2010 China Sub-national Census Population Data" can also be used in addition to the census data released by the National Bureau of Statistics and The Census Office of the State Council. Both were coedited by the National Bureau of Statistics and the State Ethnic Affairs Commission. With the participation of the State Ethnic Affairs Commission, these two databases provide important data about the specific circumstances of intermarriage in China's various ethnic groups. Both databases record information on nationwide family households in detail and take the head of a household and the ethnic identity of each spouse as statistical indicators. This detailed data on Chinese ethnic intermarriage is extremely rare. Furthermore, because it is nonsampled short form data, it covers the entire country's population. However, for researchers, there are still two flies in the ointment. The first is that the database takes China in its entirety as a statistical unit and does not provide provincial data. Therefore, regional differences in intermarriage cannot be analyzed. The second is that the data only include married-household families; single (unmarried, divorced, widowed) families are not included. It also does not indicate the marriage situation of family members who are not the heads of the household. It is therefore difficult for researchers to judge whether it was the factors that changed demographic patterns or that the different statistical standards caused the total number of purely minority households in 2010 to be less than in 2000. In other words, to carry out in-depth research, it will be necessary to obtain more specific information by other means to study the intermarriage patterns of divorced and widowed families, nonhead members of households, the marriage wishes of unmarried persons, and so forth.

Data is the important foundation of sociological ethnic intermarriage research. Although the national population census provides rich content of the index system that fits the reality population model well, a national sociological population database that can both support in-depth analysis and have realistic pertinence has not yet been formed. As a result, only very-preliminary descriptions of the related issues can be offered. To advance China's social science research on ethnic issues, scholars and relevant government departments need to work together, starting by building a basic database.

\section{China's ethnic intermarriage profiles, 1990-2010}

Size and percentage changes in the ethnic composition of Chinese households, 1990-2010

From the data provided in Table 1, the total number of households nationwide increased from 276.91 million to 340.49 million in $1990-2000$, an increase of $23 \%$. In the same period, the average size of family households fell from 3.964 to 3.461 people, down by 12.7\%. The average size of full-Han households decreased from 3.916 to 3.421 people, down by $12.6 \%$. The average size of ethnic minority households decreased from 4.547 to 
Table 1 Ethnic composition of family households in China, 1990 and 2000

\begin{tabular}{|c|c|c|c|c|}
\hline & 1990 & & 2000 & \\
\hline & Households/persons & Percent & Households/persons & Percent \\
\hline Number of households & $276,911,767$ & 100.00 & $340,491,197$ & 100.00 \\
\hline Number of persons & $1,097,776,366$ & 100.00 & $1,178,271,219$ & 100.00 \\
\hline Persons per household on average & 3.964 & - & 3.461 & - \\
\hline Number of minority households & $15,996,039$ & 5.78 & $21,463,520$ & 6.30 \\
\hline Total population of minority households & $72,726,211$ & 6.63 & $82,789,610$ & 7.03 \\
\hline Persons per minority household on average & 4.547 & - & 3.857 & - \\
\hline Minority-Han mixture households & $6,756,042$ & 2.44 & $9,121,114$ & 2.68 \\
\hline $\begin{array}{l}\text { Total population of minority/Han mixture } \\
\text { household }\end{array}$ & $29,798,457$ & 2.71 & $35,387,918$ & 3.00 \\
\hline $\begin{array}{l}\text { Persons per minority-Han mixture household } \\
\text { on average }\end{array}$ & 4.411 & - & 3.880 & - \\
\hline Number of Han households & $254,159,686$ & 91.78 & $309,906,563$ & 91.02 \\
\hline Total population of Han households & $995,251,698$ & 90.66 & $1,060,093,691$ & 89.97 \\
\hline Persons per Han households on average & 3.916 & - & 3.421 & - \\
\hline
\end{tabular}

Source: The Census Office of the State Council, ed., 1993: 840-805; 2002: 645

3.857 people, dropping $15.2 \%$, and in minority-Han mixture households, it decreased from 4.411 to 3.880 people, dropping $12 \%$. It is thus clear that during this 10 -year period the average size of Chinese family households has shown an overall decline trend. Because ethnic minority households previously had a larger average number of people, this decline was even more obvious.

The proportion of minority-Han mixture households in total households increased from $2.44 \%$ in 1990 to $2.68 \%$ in 2000 , up by $0.24 \%$ with an increase of 2.365 million households and 5.589 million people. In the same period, the proportion of full ethnic minority households in the total number of households increased by $0.52 \%$, with a gain of 10.063 million people.

If we compare the ethnic intermarriage data in the 2000 and 2010 censuses (see Table 2) and use the second type of data, the number of monoethnic households is 33.0405 million in 2000, compared to 30.9907 million Han households in Table 1. We can then calculate that the number of monoethnic minority households is 2.0498 million in 2000. By comparing this figure to 21.463 million full-ethnic minority households, it can be calculated that the number of minorities-minority intermarried households was 96.5 million in 2000.

In full ethnic minority households (members may belong to different ethnic minorities), the ethnic intermarriage households accounted for 4.49\%. Using only the 2000

Table 2 Ethnic composition of Chinese households, 2000 and 2010

\begin{tabular}{|c|c|c|c|c|c|c|c|c|c|}
\hline & \multirow{2}{*}{$\begin{array}{l}\text { Total number } \\
\text { of } \\
\text { households }\end{array}$} & \multicolumn{2}{|c|}{$\begin{array}{l}\text { Households of single } \\
\text { ethnic group }\end{array}$} & \multicolumn{2}{|c|}{$\begin{array}{l}\text { Households of two } \\
\text { ethnic groups }\end{array}$} & \multicolumn{2}{|c|}{$\begin{array}{l}\text { Households of three } \\
\text { ethnic groups }\end{array}$} & \multicolumn{2}{|c|}{$\begin{array}{l}\text { Households of four or } \\
\text { more ethnic groups }\end{array}$} \\
\hline & & Households & $\overline{\text { Percent }}$ & Households & Percent & Households & $\overline{P e r c e n t}$ & Households & Percent \\
\hline 2000 & $340,491,197$ & $330,405,023$ & 97.04 & $9,940,293$ & 2.92 & 142,875 & 0.04 & 3006 & - \\
\hline 2010 & $401,934,196$ & $390,914,616$ & 97.26 & $10,813,971$ & 2.69 & 201,512 & 0.05 & 4097 & _- \\
\hline
\end{tabular}

Source: The Census Office of the State Council, ed., 2002: 645; The Census Office of the State Council, and National Bureau of Statistics,ed., 2012:375 
data, the number of intermarriages between ethnic minorities is larger than intermarriages with those of Han nationality.

The data provided in Table 2 shows that in 2000 2.96\% of households nationwide (10,086 million) were intermarriage households, while in 2010 , it was $2.74 \%$. Thus, although the total number of intermarriage households increased from 2000 to 2010, it is clear that its proportion declined. Other than households of ethnic minority intermarriages, from 1990 to 2000, the number of minority-Han households increased by $35 \%$, $52.17 \%$ higher than the increment of households nationwide (23\%). From 2000 to 2010, the country's total households increased by $18.05 \%$, and ethnic intermarriage households increased by $9.26 \%$. The changes in intermarriage's volume in these two 10-year periods showed an opposite trend. In China, the Han population accounts for more than $90 \%$ of the total population; therefore, the largest number of intermarriages is between ethnic minorities and Han. Their intermarriage rate became the most significant statistic index, and the change in the rate reflects major changes in China's interethnic relations in these 20 years. Due to the lack of yearly statistical data, we are unable to determine on which year the trend of the change in number of ethnic intermarriages reversed; thus, we cannot perform further analysis on specific factors that affected the change. In particular, it is impossible to distinguish the impact on intermarriage between macro policy factors such as the implementation of "Western development" strategies and major interethnic relations events.

The changes in number and ratio of China's monoethnic households, 2000-2010

There are 55 ethnic minorities living in China, with very diverse population size, degree of concentration in their inhabited areas, and differences from Han culture. In different regions, the historical traditions of ethnic minorities intermarrying with Han or with other neighboring ethnic peoples are very diverse. In 2010, the population of four ethnic minorities exceeded ten million, the population of 14 ethnic minorities was between one million and ten million, the population of 18 ethnic minorities was between 100,000 and one million, the population of 13 ethnic minorities was between 10,000 and 100,000, and the population of six ethnic minorities was under 10,000. When taking the 55 ethnic minorities as a whole to analyze intermarriage data, many characters of difference of ethnic minority intermarriage will be canceled out or balanced by each other. It is thus impossible to determine the specific features of one ethnic minority mingling with another. Therefore, this paper only uses the subprovince monoethnic household data provided in Table 3 to discuss the regional characteristics of ethnic intermarriage ${ }^{2}$.

Comparing the changes in proportion of monoethnic households in the total households between 2000 and 2010, it is found that the proportion of monoethnic households dropped in seven of the country's 31 provinces, municipalities, and autonomous regions (Beijing, Shanghai, Chongqing, Guangdong, Hainan, Hubei, and Yunnan). The economy in these municipalities and provinces developed rapidly and absorbed a great deal of the floating population. Thus, the proportion of ethnic intermarriages naturally increased. In the past 10 years, the proportion of monoethnic households remained unchanged in two provinces-Sichuan and Xizang-while that in 22 provinces rose by several degrees. In the three northeastern provinces of China, the proportion of monoethnic households increased by more than $1 \%$. However, the proportion of monoethnic households increased 
Table 3 Change in percentage of households with members from a single ethnic group, 2000-2010

\begin{tabular}{|c|c|c|c|c|c|c|c|}
\hline \multirow[t]{2}{*}{ Area } & \multicolumn{3}{|l|}{2000} & \multicolumn{3}{|l|}{2010} & \multirow{2}{*}{$\begin{array}{l}\text { Change of } \\
\% \text { during } \\
2000-2010\end{array}$} \\
\hline & $\begin{array}{l}\text { Total } \\
\text { households }\end{array}$ & $\begin{array}{l}\text { Households of } \\
\text { single ethnic } \\
\text { group }\end{array}$ & Percent & $\begin{array}{l}\text { Total } \\
\text { households }\end{array}$ & $\begin{array}{l}\text { Households of } \\
\text { single ethnic } \\
\text { group }\end{array}$ & Percent & \\
\hline Total & $340,491,197$ & $330,405,023$ & 97.04 & $401,934,196$ & $390,914,616$ & 97.26 & +0.22 \\
\hline Beijing & $4,096,844$ & $3,926,838$ & 95.85 & $6,680,552$ & $6,450,814$ & 96.56 & -0.71 \\
\hline Tianjin & $2,976,741$ & $2,926,529$ & 98.31 & $3,661,992$ & $3,602,585$ & 98.38 & +0.07 \\
\hline Hebei & $17,934,977$ & $17,498,176$ & 97.56 & $20,395,116$ & $19,911,449$ & 97.63 & +0.07 \\
\hline Shanxi & $8,650,261$ & $8,621,246$ & 99.56 & $10,330,207$ & $10,311,704$ & 99.82 & +0.26 \\
\hline Inner Mongolia & $6,784,470$ & $5,982,730$ & 88.18 & $8,205,498$ & $7,251,661$ & 88.38 & +0.20 \\
\hline Liaoning & $12,866,262$ & $11,506,381$ & 89.43 & $14,994,046$ & $13,601,061$ & 90.71 & +1.28 \\
\hline Jilin & $7,848,446$ & $7,414,954$ & 94.48 & $8,998,492$ & $8,634,968$ & 95.96 & +1.48 \\
\hline Heilongjiang & $10,955,750$ & $10,515,610$ & 95.98 & $13,000,088$ & $12,677,743$ & 97.52 & +1.54 \\
\hline Shanghai & $5,299,068$ & $5,263,946$ & 99.34 & $8,253,257$ & $8,185,122$ & 99.17 & -0.17 \\
\hline Jiangsu & $21,375,726$ & $21,253,315$ & 99.43 & $24,381,782$ & $24,265,781$ & 99.52 & +0.09 \\
\hline Zhejiang & $14,136,916$ & $14,032,536$ & 99.26 & $18,854,021$ & $18,649,455$ & 98.92 & +0.66 \\
\hline Anhui & $16,313,885$ & $16,216,199$ & 99.40 & $18,861,956$ & $18,770,159$ & 99.51 & +0.11 \\
\hline Fujian & $8,743,252$ & $8,590,661$ & 98.25 & $11,206,317$ & $11,027,362$ & 98.40 & +0.15 \\
\hline Jiangxi & $10,168,639$ & $10,105,557$ & 99.38 & $11,542,527$ & $11,487,422$ & 99.52 & +0.14 \\
\hline Shandong & $26,709,328$ & $26,606,762$ & 99.62 & $30,105,454$ & $30,015,513$ & 99.70 & +0.08 \\
\hline Henan & $24,247,377$ & $24,089,034$ & 99.35 & $25,928,729$ & $25,803,651$ & 99.52 & +0.17 \\
\hline Hubei & $15,613,793$ & $15,264,291$ & 97.76 & $16,695,121$ & $16,317,679$ & 97.74 & -0.02 \\
\hline Hunan & $17,662,105$ & $16,949,978$ & 95.97 & $18,625,710$ & $17,894,348$ & 96.07 & +0.10 \\
\hline Guangdong & $18,762,127$ & $18,602,344$ & 99.15 & $28,630,609$ & $28,351,454$ & 99.02 & -0.13 \\
\hline Guangxi & $11,309,236$ & $10,161,715$ & 89.85 & $13,151,404$ & $11,871,454$ & 90.27 & +0.42 \\
\hline Hainan & $1,750,710$ & $1,676,820$ & 95.78 & $2,331,149$ & $2,230,302$ & 95.67 & -0.11 \\
\hline Chongqing & $9,141,558$ & $8,855,904$ & 96.88 & $1,0000,965$ & $9,763,487$ & 97.63 & -0.25 \\
\hline Sichuan & $23,638,429$ & $23,437,944$ & 99.15 & $25,794,161$ & $25,575,506$ & 99.15 & 0.00 \\
\hline Guizhou & $9,239,409$ & $8,028,348$ & 86.89 & $10,558,461$ & $9,237,899$ & 87.49 & +0.60 \\
\hline Yunnan & $10,853,172$ & $9,774,030$ & 90.06 & $12,339,961$ & $10,980,454$ & 88.98 & -1.08 \\
\hline Xizang & 531,571 & 524,228 & 98.62 & 670,838 & 661,550 & 98.62 & 0.00 \\
\hline Shaanxi & $9,429,484$ & $9,404,073$ & 99.73 & $10,718,563$ & $10,690,535$ & 99.74 & +0.01 \\
\hline Gansu & $6,086,988$ & $5,994,185$ & 98.48 & $6,900,369$ & $6,797,183$ & 98.50 & +0.02 \\
\hline Qinghai & $1,173,977$ & $1,101,750$ & 93.85 & $1,529,039$ & $1,438,341$ & 94.07 & +0.22 \\
\hline Ningxia & $1,396,870$ & $1,368,753$ & 97.99 & $1,882,205$ & $1,844,877$ & 98.02 & +0.03 \\
\hline Xinjiang & $4,793,826$ & $4,710,186$ & 98.26 & $6,705,607$ & $6,613,097$ & 98.62 & +0.36 \\
\hline
\end{tabular}

Source: Population Census Office of the State Council \& State Statistical Bureau, eds.,2002: 645;2012: 375

comparatively largely in the following provinces: Zhejiang (+0.66\%), Guizhou $(+0.6 \%)$, Guangxi (+0.42\%), and Xinjiang (+0.36\%). These areas are located in the eastern coast, southwest, and northwest of China. In addition, Shanxi province, with a middle level of socioeconomic development, increased by $0.26 \%$.

Based on the above data, if we take the province as an analytical unit, the change in ethnic intermarriage does not show a simple correspondence to language, cultural, and socioeconomic development. Using the proportion of monoethnic households as an 
index, ethnic intermarriage in Beijing, Shanghai, and Guangdong, three rapidly developing economic areas, is similar to that in Hubei and Yunnan, where the economy developing relatively slowly and with fewer migrants. Meanwhile, the Western development center Sichuan is similar to Tibet, where the province has extremely low population density. In addition, the monoethnic-household ratio rose sharply in both Zhejiang and Guizhou provinces. The former is experiencing rapid economic development and the latter has the slowest growing economy.

Since the constitution of the ethnic population, communication conditions, and interaction history of ethnic groups in different regions are diverse, understanding the local characteristics of ethnic intermarriage in different provinces and regions requires carrying out further investigation to determine specific factors. Without subregional statistical data, only using sweeping data such as that on monoethnic households or taking administrative divisions as units to study the status of ethnic intermarriage cannot effectively illustrate the structural characters of Chinese ethnic intermarriage. In addition, since we do not know which ethnicities are involved in marriages of nonmonoethnic households, the above statistical indicator has limited value in in-depth analysis.

\section{The evolving mode of ethnic intermarriage, 2000-2010}

As mentioned above, the "Chinese ethnic population data in the 2000 census" and "2010 China Sub-national Census Population Data” provide rare and valuable data. The two databases were coreleased by the National Bureau of Statistics and State Ethnic Affairs Commission, which recorded the information obtained from these two censuses, such as ethnic identity for the head and spouse in households nationwide. Through this information, we can obtain the subethnic intermarriage data on the head and spouse of each household. However, as mentioned before, these countrywide statistics do not present the difference in the characteristics of ethnic intermarriage in various regions. For example, the Hui ethnicity, scattered in big cities in eastern China, has quite a different social atmosphere and marriage habits compared to the Hui people who inhabit the northwestern Gansu-Qinghai region where strong religious traditions exist. Limited by the published data, we are unable to distinguish regional characteristics from the nationwide data.

Many of China's 55 ethnic minority groups have a small population size. In order to control the article's length, Table 4 only includes 18 ethnic minorities whose population size is listed as more than one million in the 1990 census. Their total population was 111.97 million, accounting for $93.67 \%$ of the total population of all ethnic minorities in China. These 18 minority groups can thus represent the country's minority population.

In order to compare the intermarriage situations of all ethnic groups in 2000 and 2010, we took the total number of the heads of each ethnic household in the census in Table 4 as 100 and calculated the number of intermarriages with other ethnic groups as a percentage. In order to narrow the focus, in the "ethnic group of spouse" column, except for spouses of the same ethnic group ("intraethnic marriage"), Table 4 lists only ten larger ethnic groups that had a large proportion of intermarriage with other groups and sorted by size of marriage ratio. In addition, the proportion of a plurality of rows in the ten ethnic groups is less than $1 \%$ of the total number of intermarriages, so in Table 4, we omitted those objects whose ethnic intermarriage ratio was behind the first ten groups. 


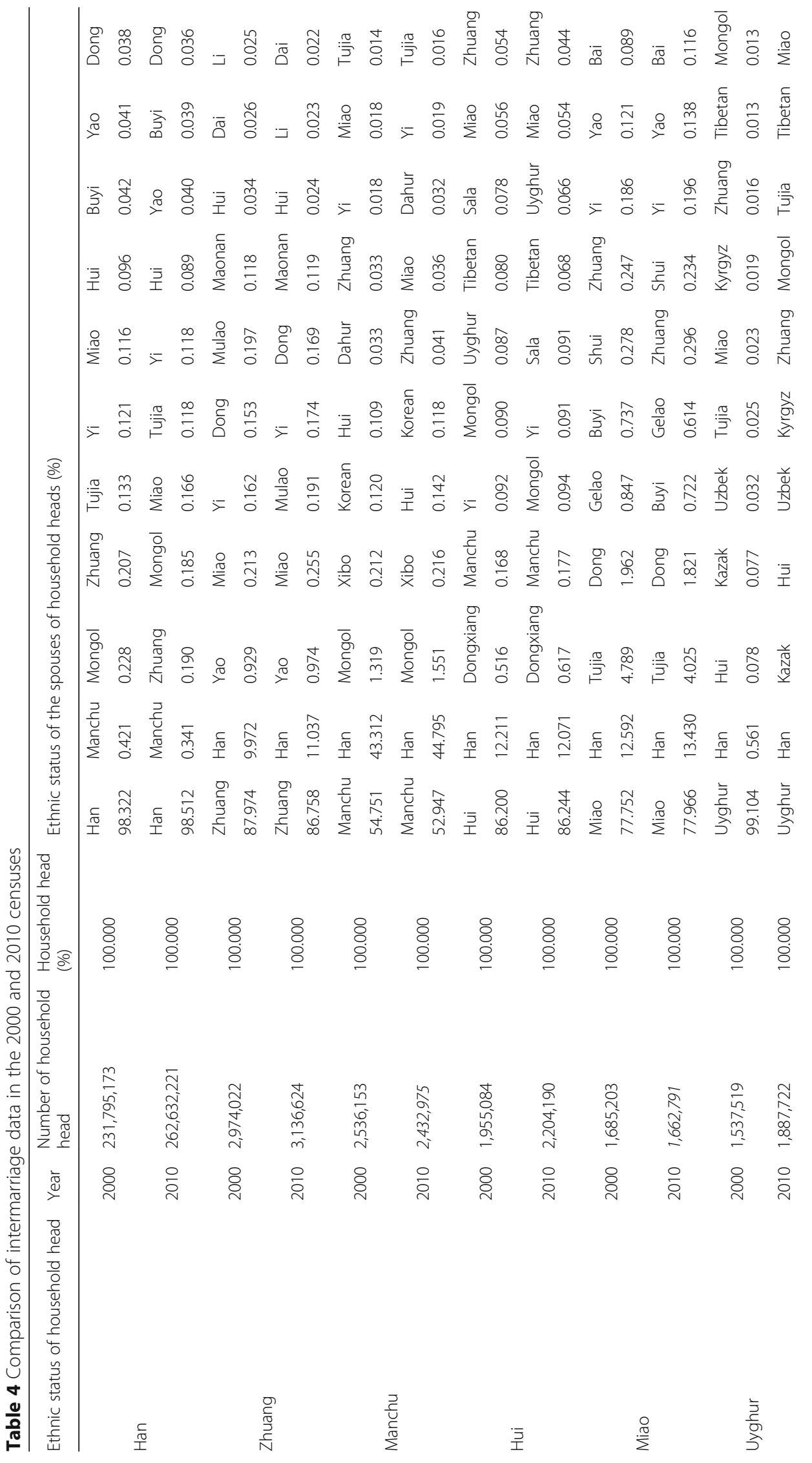




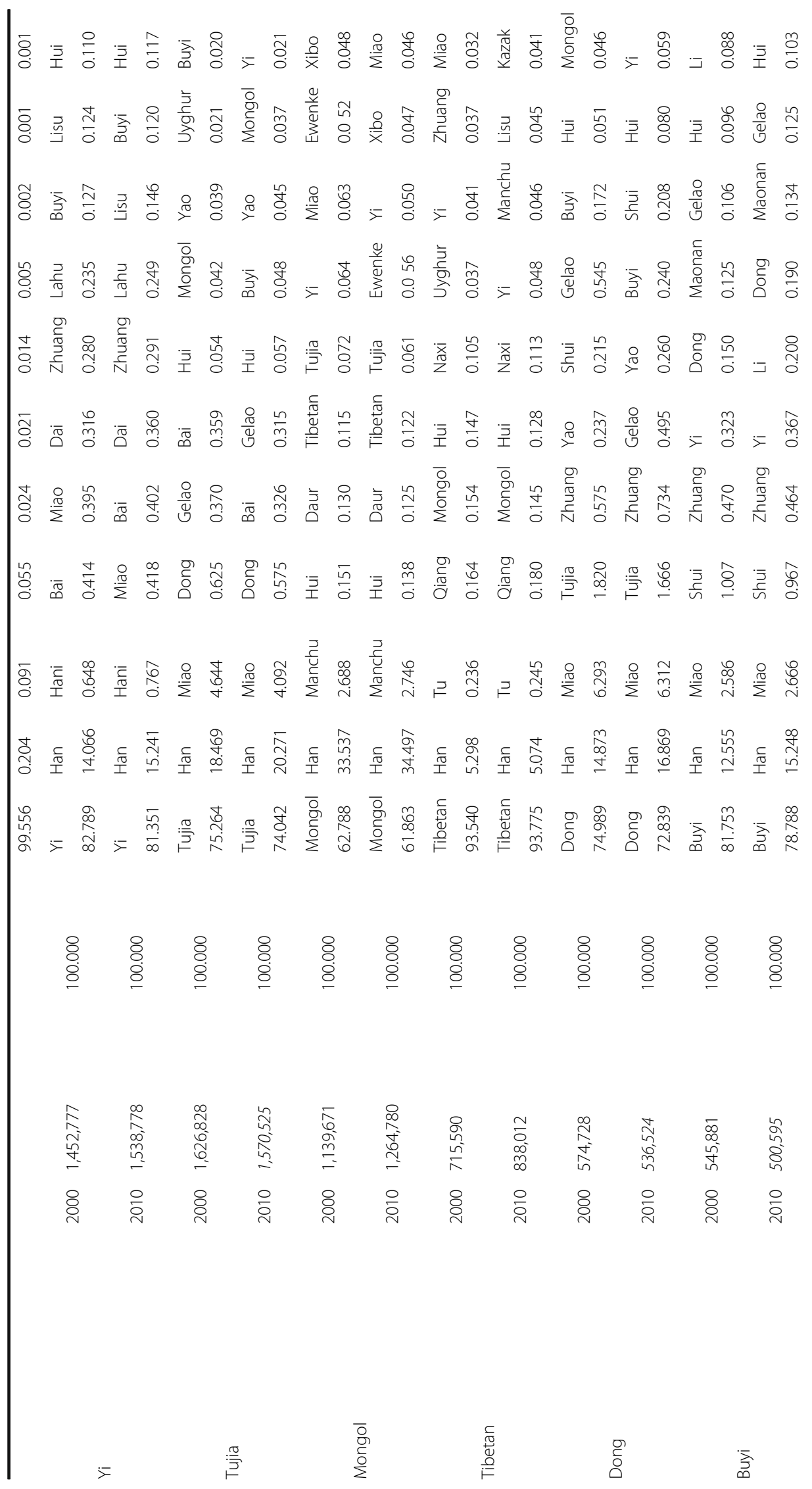




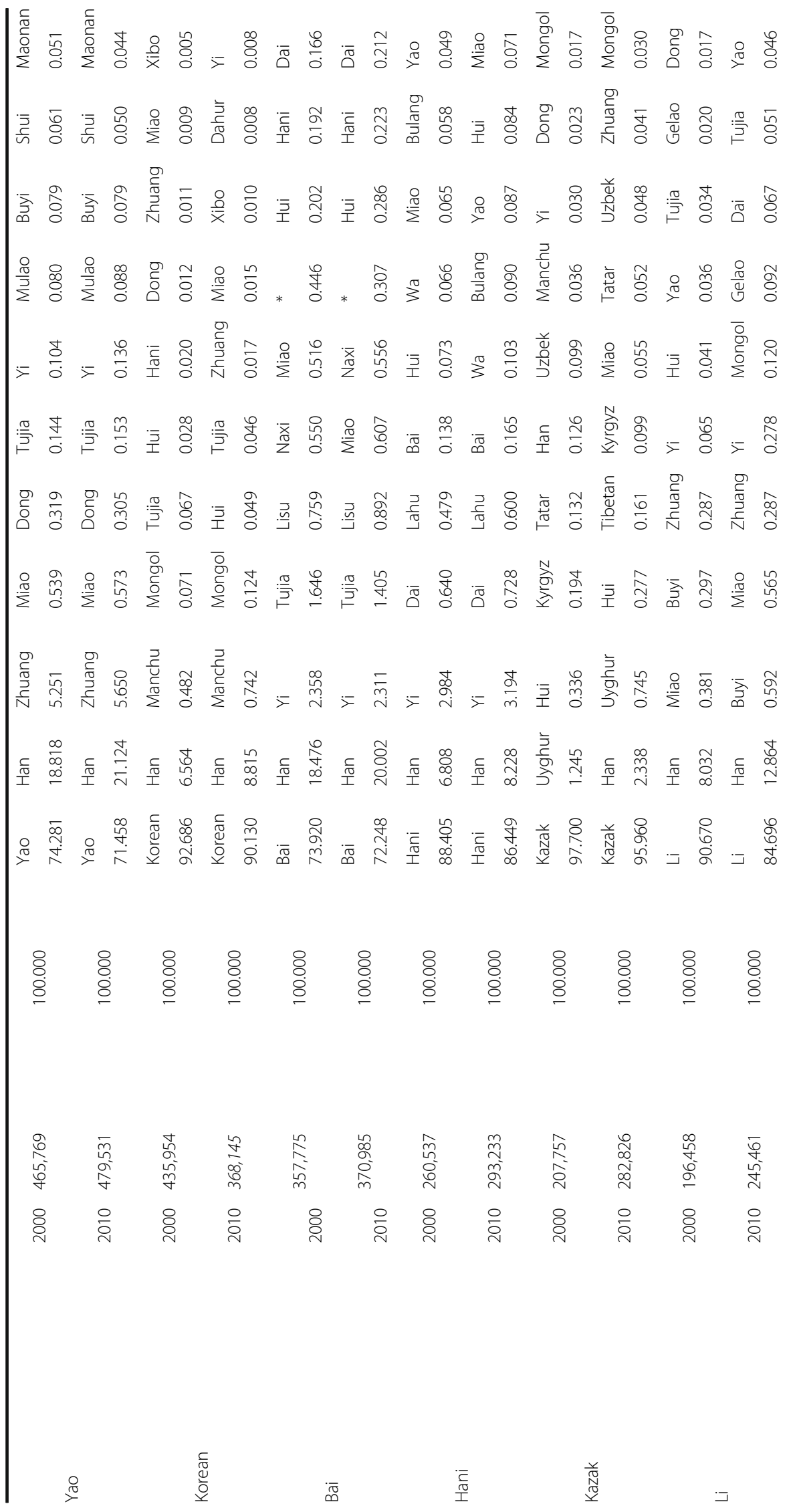




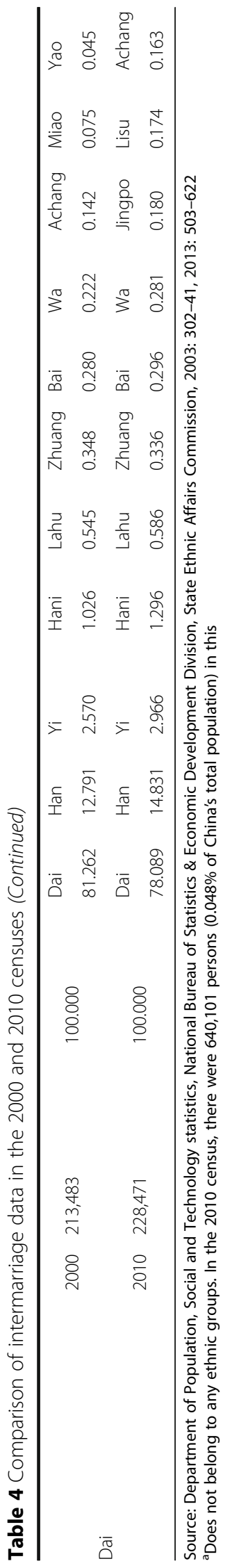




\section{Spouse change in ethnic intermarriages, 2000-2010}

From Table 4, we can summarize the following characteristics of China's ethnic intermarriage for the period 2000-2010.

First, the total number of "complete-couple households" that claimed a native ethnic as the head of household declined in Manchu, Miao, Tujia, Dong, Buyi, and Korea for six ethnic minorities. This was because a large number of young people of these ethnic minorities tend to marry late, and the single population had increased. Compared with the above six ethnic minorities, the number of "complete-couple households" of Uyghur, Tibetan, Han, Hui, Mongolian, Yi, and Zhuang increased significantly. Their increasing rates were $22.8,17.1,13.3,12.7,5.9$, and $5.5 \%$, respectively. This could indicate that these ethnic groups are more likely to maintain intact families, and the marriageable age of young people are relatively early. In particular, the substantial growth of number of Uyghur complete-couple households reflects the fact that due to rapid population growth caused by Uighur's high fertility in recent decades, a large number of young people entered marriage age and started a family. As a result, the number of new households increased over $20 \%$ in 10 years.

Second, apart from the Han nationality, in 2010, the highest proportions of intraethnic marriage were by Uyghurs, Kazaks, Koreans, and Tibetans. Viewing the trend of change in ethnic intermarriage rates from 2000 to 2010, the proportion of intraethnic marriage households in the total households of each ethnic group rose in only five ethnic groups with large populations: Han, Hui, Miao, Uyghur, and Tibetan. The proportion of intraethnic marriage households of the remaining 14 ethnic groups in Table 4 declined, indicating that the country's ethnic intermarriage has an overall growth trend. The reasons leading to the rise of intraethnic-marriage rates in these five key ethnic groups are various. If taking into account, the factors of level of settlement and relative population size, the Han and Hui populations have a wider geographical distribution throughout the country's provinces and autonomous regions, but the Uyghurs settled mainly in southern Xinjiang, the Tibetans settled in the Tibet area, and the Miao are scattered in the southern provinces. This indicates that a general pattern does not exist at this point. If viewed from the cultural difference dimension, the Uyghur and Hui peoples who settled in groups both have strict customs and taboos due to their Muslim beliefs. The Tibetan and Han have a common Buddhist faith while the Miao have no special religious beliefs, so cultural differences are not sufficient to explain their common high proportion of intraethnic marriage. This also indicates the limitations of the database, which does not present regional differences that would help researchers conduct further in-depth analysis and comparison.

Third, in 2010, the first choice of an intermarriage spouse in China's 18 major ethnic minorities was Han. Since the Han people account for $91.5 \%$ of the national population, viewed from the perspective of relative size, an important factor in ethnic intermarriage research (Blau 1991: 34-35), it is a quite natural phenomenon that the Han should be the main target of intermarriage for other ethnic groups. Taking the proportion of households intermarrying with Han in total minority-headed households as an indicator, the first 13 ethnic groups sorted in descending order are Manchu, Mongolian, Yao, Tujia, Bai, Dong, Buyi, Yi, Dai, Miao, Li, Hui, and Zhuang. When the rate of intermarriage between two ethnic groups exceeds $10 \%$, it is generally considered as andicator 
of relatively harmonious interaction. The rates between the above 13 ethnic groups and the Han are all higher than $10 \%$.

In contrast, the lowest rate of Chinese ethnic intermarrying with Han is the Uygur, the second lowest is the Kazak, and Tibetans are the third lowest. Tibetan, Uyghur, and Kazak people are highly populated in ethnic autonomous areas (Qinghai-Tibet Plateau, the northern Xinjiang pastoral, and southern Xinjiang, respectively) where Han people rarely reside. These three ethnic minorities have significant differences from the Han in language, religious customs, living habits, and other aspects. The ratio of Tibetans in the total population of the Tibet Autonomous Region is as high as $90 \%$. In the southern Xinjiang Hotan and Kashi areas, the Uyghur account for over $90 \%$ of the total local population. Relative population size is also an important factor restricting Tibetan-Han and Uyghur-Han intermarriage (Ma Rong 1996). Nomadic Kazaks also differ from the agricultural population in language, religion, social organization, and patterns of living and production, creating some real obstacles for ordinary Kazak people to marry Han and other ethnic minorities.

However, the changes in the intermarriage patterns of Kazaks in the past 10 years need to be particularly noted. In 2000, the largest ethnic group intermarrying with Kazaks was Uyghurs. The households of intermarried Kazak-Uyghur totaled 2587, and Kazak-Han were only 261. By 2010, the number of Kazak-Uyghur households had decreased to 2106, while Kazak-Han households increased to 6612. The significant changes that occurred in Kazak intermarriage in these 10 years reflect the new trend of ethnic interaction of young Kazak people.

Fourth, the cases of several northwest Islamic ethnic groups show that religion may be an important factor affecting ethnic intermarriage. The Uyghur have the strongest endogamy tendency of all Chinese ethnic groups. In addition to intermarrying with the Han (0.2\%), other ethnicities intermarrying with the Uyghur, listed in descending order, are Hui, Kazakh, and Uzbek. The ratios are all lower than $0.1 \%$, showing the Uyghur's high level of closure. The number of Hui people living in Xinjiang area has reached 98.3 million, accounting for $9.3 \%$ of the country's total Hui population. However, throughout the country, only 1464 Hui-headed households intermarried with the Uygur, accounting for $0.066 \%$ of the total Hui-headed households or $0.15 \%$ of the Hui population in Xinjiang. Meanwhile, only 1029 Uyghur-headed households intermarried with Hui, accounting for $0.055 \%$ of the total Uygur-headed households. In Hui-Uyghur intermarriage, the common Islamic faith does not seem to close the emotional distance between the two ethnic groups. Their intermarriage rates were both lower than the intermarriage rates with the Han.

Fifth, dozens of ethnic minorities have lived in the southwest provinces of China since the Ming and Qing dynasties. The mixing and living together of ethnic groups was quite common, and mutual exchanges and cooperation in economic and cultural life existed over a long period of time. The Chinese government set up 16 autonomous prefectures and 76 autonomous counties for the identified and named ethnic minorities in Guangxi, Guizhou, Yunnan, Sichuan, Chongqing, and other places. Nearly all ethnic groups in every autonomous county are in a mixed living pattern. With a common geographic climate and natural resources, the residents of all ethnic groups participate in the same economic activities, share food habits and architectural styles of local residences, pray together for harvest, and celebrate the holidays. These life patterns inevitably bring a higher rate of ethnic intermarriage. 


\section{Analysis of factors affecting the change of spouse in ethnic intermarriage}

Previously the paper introduced the model recommended by Ma Rong to analyze the factors affecting ethnic intermarriage, but the data on many variables of the model cannot be obtained due to limited data conditions. Thus, herein, we set a relatively simple path analysis model by using some core variables. These variables reflect several social structural characteristics of ethnic groups and are provided by the population census (see Fig. 2).

In this model, the popularity of Mandarin (Putonghua) and the concentration degree of the population's inhabitation are utilized as two indexes in addition to statistical data. As a daily communication tool, language is an important structural element of ethnic intermarriage. The general degree of using the same language has important implications for ethnic groups' communication and integration. According to the conditions of education, communication, and daily language usage, the author roughly divided the 18 ethnic groups whose population is more than one million into six groups (see Table 5). The sequence of each group in Table 5 reflects the degree of the usage of the native language, the popularity of the common national language (Mandarin) in the 18 ethnic minorities, and the degree of mixed usage of ethnic languages. These groups can be roughly divided into two large categories: the ethnic groups in the sixth type of "language usage" in Table 5 belong to one category which still practice their own ethnic language usage; another category accounts for the ethnic groups in the rest five types of language usage in Table 5, who speak either only the national common language (Mandarin) or both the mother tongue and the national common language to different degrees.

The living patterns of China's ethnic groups are often summed up as "big scattered, small settlements." The term "big scattered" means all ethnic groups are generally living mixed together, while "small settlements" refers to only a few ethnic groups living in an area or a smaller population of ethnic minorities in a small area. For instance, the Hui people are distributed throughout the country with typical "big scattered" features; however, in the Ningxia Hui autonomous region where the Hui population accounts for one-third of the region's population, the Hui mainly settled in the southern area, which is known as "small settlements." After the founding of the People's Republic of China, the Chinese government has established autonomous areas or nationality townships for the minority ethnic groups according to their population distribution. In relatively populated areas, it has established autonomous regions, autonomous prefectures, and autonomous counties based on the population size and distribution. In regions where multiethnic groups live together and with a higher proportion of minority population, the government has established two ethnics, three ethnics, or multiethnic cogovernance autonomous areas. These autonomous areas usually have a higher rate of intermarriage.

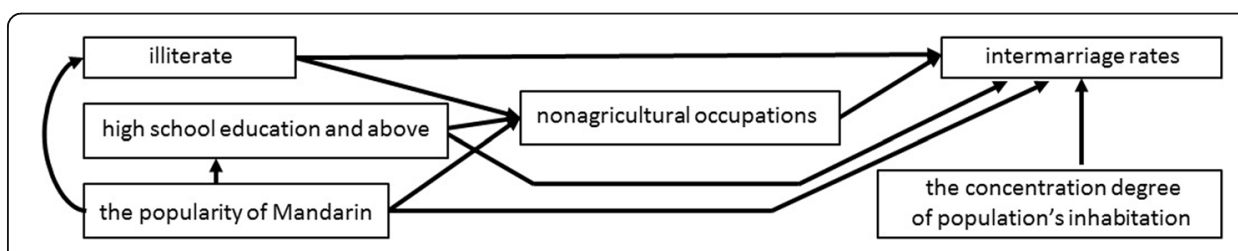

Fig. 2 The analysis model of factors influencing intermarriage rates 
Table 5 Conditions of language use of 18 ethnic groups

\begin{tabular}{lll}
\hline Ethnic group & $\begin{array}{l}\text { Language } \\
\text { usage }\end{array}$ & Detailed information \\
\hline Manchu, Hui & 1 & Mother language is Mandarin \\
Tujia, Zhuang & 2 & $\begin{array}{l}\text { Several vernaculars only used in tall timber; preliterate or } \\
\text { created words are not used; Mandarin is popular }\end{array}$ \\
Yao, Li, Hani, Bai & 3 & $\begin{array}{l}\text { Bilingualism, use Chinese characters } \\
\text { Miao, Dong, Buyi }\end{array}$ \\
$\begin{array}{ll}\text { Mandarin and Chinese characters are popular, also use } \\
\text { several vernaculars in settlement areas and created words } \\
\text { in primary publishing and education. }\end{array}$ \\
$\begin{array}{l}\text { Ethnic languages with traditional writing systems are } \\
\text { popular in settlement areas and used in primary and } \\
\text { secondary education, publishing, and other media in the } \\
\text { governments of autonomous areas. Mandarin and Chinese } \\
\text { characters are both used popularly. } \\
\text { Ethnic languages and their writing systems are in common } \\
\text { use with complete modern school systems and media institutes. }\end{array}$ \\
$\begin{array}{l}\text { Uyghur, Kazak, Tibetan, Mongol, } \\
\text { Korean }\end{array}$ \\
$\begin{array}{l}\text { Source: The Institute of Ethnology and Anthropology, } \\
\text { Division, State Ethnic Affairs Commission, 1994 Academy of Social Sciences, and the Culture and Publicity }\end{array}$
\end{tabular}

Because of this, when analyzing the factors that can influence the population distribution and living pattern of ethnic intermarriage, we use the proportion of various ethnic groups' population in single-ethnic autonomous areas as a measure. As shown in Table 6, the proportion of self-governing living in ethnic autonomous areas is the ratio of the sum population of this ethnic group in all levels of local ethnic autonomous areas and the ethnic group's total population of the country. The Buyi people have no

Table 6 Related data of 18 ethnic minorities in 2010 (in descending order of intermarriage rate)

\begin{tabular}{lllllll}
\hline Ethnic group & Intermarriage rate & Illiteracy & $\begin{array}{l}\text { High school } \\
\text { education } \\
\text { and above }\end{array}$ & Nonagricultural & $\begin{array}{l}\text { Population } \\
\text { inhabitation } \\
\text { in autonomous } \\
\text { area }\end{array}$ & $\begin{array}{l}\text { Popularity of } \\
\text { Mandarin }\end{array}$ \\
\hline Manchu & Percent & Percent & Percent & Percent & Percent & \\
Mongol & 38.137 & 2.14 & 24.58 & 41.55 & 23.12 & 1 \\
Yao & 28.542 & 3.31 & 29.91 & 36.75 & 77.29 & 6 \\
Bai & 27.752 & 6.67 & 14.37 & 26.19 & 24.64 & 3 \\
Dong & 27.161 & 5.83 & 18.93 & 33.33 & 57.54 & 3 \\
Tujia & 25.958 & 6.62 & 15.61 & 36.64 & 27.63 & 4 \\
Miao & 22.034 & 6.11 & 19.49 & 39.80 & 13.66 & 2 \\
Dai & 21.911 & 10.25 & 11.68 & 29.60 & 9.75 & 4 \\
Buyi & 21.212 & 11.29 & 10.17 & 19.54 & 25.07 & 5 \\
Yi & 18.649 & 12.23 & 11.01 & 30.71 & 0 & 4 \\
Li & 15.304 & 14.30 & 9.54 & 17.42 & 42.61 & 5 \\
Hui & 13.756 & 6.49 & 13.72 & 18.76 & 36.25 & 3 \\
Hani & 13.551 & 8.57 & 22.17 & 47.28 & 32.04 & 1 \\
Zhuang & 13.242 & 14.52 & 8.64 & 21.30 & 13.38 & 3 \\
Korean & 9.87 & 4.75 & 16.35 & 30.79 & 85.36 & 2 \\
Tibetan & 6.225 & 1.29 & 41.83 & 73.64 & 40.79 & 6 \\
Kazak & 4.040 & 30.56 & 10.26 & 17.04 & 83.43 & 6 \\
Uyghur & .444 & 1.59 & 21.08 & 22.43 & 79.38 & 6 \\
\hline & 3.51 & 12.93 & 17.26 & 99.32 & 6 \\
\hline
\end{tabular}


separate ethnic autonomous area and only jointly built two autonomous prefectures and three autonomous counties with other ethnic minorities. Thus, the indicator value for the Buyi is zero in Table 6 .

Using the data from Table 6, the statistical result of bivariate correlation analysis shows that the correlation coefficient between ethnic intermarriage rates and the other five variables was not statistically significant. A high statistically significant correlation only occurs between illiteracy and high school education $(r=-0.594, p<0.01)$, as well as high school education and nonagricultural occupations $(r=-0.866, p<0.01)$, indicating that a linear causal relationship between these variables was not significant.

The results of path analysis on the factors that affect intermarriage in the analysis model in Fig. 2 are shown in Fig. 3. The statistical significance level is low (less than 0.2\%) due to only using 18 samples. However, the results still provide some information.

First, in the four variables that can influence the intermarriage rate, the level of education (high school graduation) on the positive impact of intermarriage is most significant. This is because those with high school and college education usually have more opportunities to associate with youth from other ethnic groups, and therefore, the chances of dating and marriage increase.

Second, the application direction of the second factor, the nonagricultural occupation rate, is contrary to the expectation. The calculation result shows that the intermarriage rates of those ethnic groups with high proportions of nonagricultural occupations are rather low (-0.985). For example, Koreans' proportion of nonagricultural occupations reached $73.64 \%$, while the ethnic intermarriage rate was only $9.87 \%$. In the occupational structure of the population of Uighurs, Kazaks, Tibetans, and Koreans, the four ethnic groups with the lowest intermarriage rates, the categories of head of party institutions, professional technicians, and clerks accounted for 38.47, 43.19, 50.41, and 32.37\%, respectively, of the nonagricultural occupational population. For the Manchu, Mongolians, Yao, and Bai, the four ethnic groups with the highest intermarriages rates, the above personnel account for $31.62,45.63,24.63$, and $30.12 \%$, respectively. In addition to the Yao, the rates of all the remaining ethnic groups are higher than the Han (24.81\%) (The Census Office of the State Council, and National Bureau of Statistics 2012).

The occupational structure of China's ethnic minority suggests that the intermarriage tendency of ethnic cadres may have a greater impact on the intermarriage rates of all ethnic groups. A substantial proportion of Party and government officials, and professional and technical personnel are highly educated. The ethnic theory taught at the university level has enhanced the national/ethnic consciousness and further

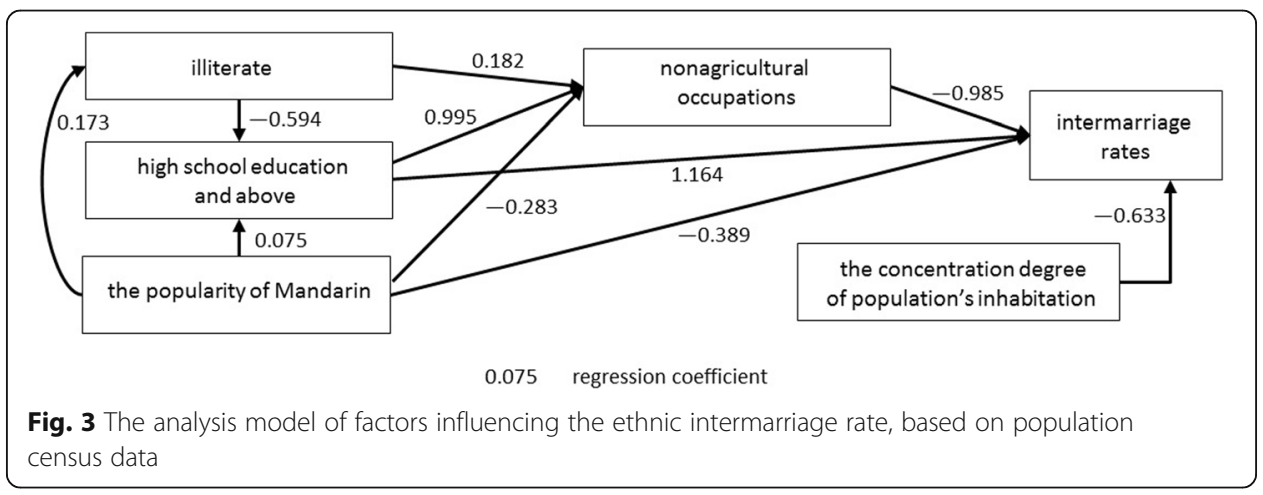


strengthened the endogamy orientation of ethnic college students. In this way, the higher education structure and occupational structure play a role in the ethnic intermarriage phenomenon. The calculation results of the two indicators of education level and nonagricultural occupation suggest that secondary education likely makes a greater contribution to ethnic intermarriage, whereas the proportion of higher education does not necessarily have a positive correlation with the intermarriage rate. This is quite different from the general patterns of ethnic intermarriage in other countries. Due to limited space, this paper does not discuss this matter in depth.

The third factor is the residential ratio in ethnic groups' own autonomous areas. The higher the proportion of population living in local autonomous areas is, the smaller the chance of intermarriage with other ethnic groups is. The fourth variable is the degree of popularity of the national common language (Mandarin). When it is less popular, the opportunities for interaction and intermarriage with other ethnic groups are fewer. The four ethnic minorities with the lowest rates of intermarriage have one thing in common-they all use their native languages and writing. Although Mongolians have their own language system, the ethnic intermarriage rate of Mongolians is quite high. This may be because nearly half of the Mongolians who live in towns and agricultural areas use Mandarin in daily life, and Mongolians only account for $17 \%$ of the population of the Inner Mongolia autonomous region. The high rate of intermarriage between Mongolians who speak Mandarin and Han people has become a matter of course due to their wide interaction. Except for the influence of language and demographic factors, the low intermarriage rate of Tibetan and Kazakh may be related to the high proportion of the population engaged in animal husbandry. Due to the absence of population statistics on Mongolian animal husbandry, we are unable to discuss the ethnic intermarriage status in Mongolian pastoral areas.

Living patterns and language usage are objective differences, and economic lifestyles and religious beliefs are objective difference as well. Many studies have demonstrated that ethnic intermarriage is restricted by objective differences, but in sociological analysis, it is more meaningful to focus on the impact of influencing factors besides these objective differences. For example, the objective differences between the Zhuang and the Han are not necessarily greater than that of the Manchu and Mongolians, but the rate of Zhuang-Han intermarriage is only about one-third of Manchu-Han and Mongolian-Han. This phenomenon needs more analysis and description.

Fourth, the second level analysis taking nonagricultural occupation as a dependent variable indicates that the three variables of high school or higher education, popularization of the national common language (Mandarin), and the illiteracy rate are associated with a higher proportion of nonagricultural occupations. The illiteracy rate, which is expected to significantly affect the proportion of high school or higher education, is not as relevant as we expected, indicating that some ethnic groups have a higher illiteracy rate, as well as that a certain proportion of young people go beyond a high school education. This most likely indicates that high school and university education has been increasing very rapidly in these ethnic groups in recent years. There is only a low correlation $(r=0.075)$ between the popularity of a national common language and the proportion of receiving a high school or above education. This suggests that since 1949, the government has established a school system for some minority groups by using their mother language as the instruction language. Many members of these ethnic 
groups are highly educated, but the national language has not been popularized in their inhabited areas. This can also explain why the factor of Mandarin's unpopularity does not significantly impact the illiteracy rate.

In the above analysis, we used national data, took "nation/ethnic" as a statistical unit, and only used 18 cases as samples. There are obvious differences existing in various ethnic minorities and among the people who are in the same ethnic minority but living in different regions. To a large extent, all these factors limit the application and effectiveness of statistical analysis methods. However, the logical relationships between variables revealed in the above analysis can provide some ideas for researchers. This also demonstrates that further in-depth quantitative research on ethnic relations must take ethnic groups as the object and be based on data from specific areas so as to avoid interference from ethnic and regional differences in data analysis.

\section{Discussion}

The rate of intermarriage is a comprehensive index for measuring ethnic relations. It clearly indicates the nature and intensity of relationships of all ethnic groups in actual social life because the occurrence of ethnic intermarriage requires a series of objective social conditions. These include both sides of the marriage having wide contact opportunities, language communication, and similar social status. Intermarriage also needs willingness and intention on both sides, as well as certain requirements for the strength of identity consciousness and psychological distance of ethnic groups. Furthermore, ethnic intermarriage can only be achieved by acceptance or support from both families, relative networks, and their ethnic communities.

The phenomenon of ethnic groups' relationship in Chinese history and in other multiethnic countries indicates that intermarriages and mutual fusion is a social development trend in the sustained and benign interactive process of ethnic groups. The theory of the nature and relationship of ethnic groups advocated by the government and intelligentsia, and the related system and policy formulated by the government are all important methods for guiding their benign interactions. We need to rationally face the fusion phenomenon of various ethnic groups that occurs in the history and reality of China, as well as study it in-depth.

In the twenty-first century, China is facing severe challenges home and abroad. It must safeguard ethnic unity and promote positive interactions between ethnic groups, respect group differences while neither strengthening nor solidifying differences, but gradually narrow the gap through mutual participation in economic and social activities. Through a multidirectional communion of ethnic culture, it must gradually strengthen mutual understanding and tolerance of existing differences, together with building an inclusive Chinese culture that contains the cultural essence of all ethnic groups. We must recognize the actual needs of communication and infusion among various ethnic groups. This is the general direction of China's historical development of ethnic relations, and the increase in intermarriage among ethnic groups is the embodiment of this general direction.

\section{Endnotes}

${ }^{1}$ Since the Minzu Work Conference held in Qingdao City in the 1957, the Chinese term "minzu" in Chinese government documents and social life has been generally 
applied at two levels. One is "Zhonghua minzu" which refers to the Chinese nation, another refers to ethnic groups in China including the Han majority and many "shaoshu minzu" (minority minzu). Because the application of this term (minzu) has caused much confusion, some scholars suggest to distinguish the terms and call Zhonghua minzu as "Chinese nation" while 56 minzu as "ethnic groups" (zuqun in Chinese term, which is now widely used to translate English word "ethnic group") (Ma, 2000). Although there has no consensus among the Chinese scholars about the term adjustment yet, author applies the term of "ethnic groups" at the level of 56 minzu (Han, Mongol, Tibetan, etc.) in this paper.

${ }^{2}$ Since there was no further subprovince or subethnic data in the released census reports, we can only do some analyses based on the available data.

\section{Acknowledgements}

The research for this paper was conducted with the generous support of Ma Rong, Qu Jingdong, Guo Zhigang, and Li Xiaoxia. Also, the referees and editors are gratefully acknowledged.

\section{Author's contributions}

The whole research and the manuscript were completed by the author solely.

\section{Competing interests}

The author declares that he has no competing interests.

\section{Publisher's Note}

Springer Nature remains neutral with regard to jurisdictional claims in published maps and institutional affiliations.

Received: 12 April 2017 Accepted: 22 June 2017

Published online: 08 July 2017

\section{References}

Alba, Richard. 1990. Ethnic Identity: The Transformation of White America. New Haven, CT: Yale University Press. Blau, Peter. 1991. Inequality and Heterogeneity. Beijing: China Social Sciences Press.

The Census Office of the State Council (ed.). 1993. 1990 Population Census of China, vol. 1. Beijing: China Statistics Press.

The Census Office of the State Council (ed.). 2002. Tabulation on the 2000 Population Census of the People's Republic of China, vol. 1. Beijing: China Statistics Press.

The Census Office of the State Council, and National Bureau of Statistics (ed.). 2012. 2010 Population Census of China, vol. 1. Beijing: China Statistics Press.

Chen, Mingxia. 1993. Exploration on the Issue of Ethnic Intermarriages. Ethno-National Studies 4: 18-28.

Department of Population, Social Science and Technology Statistics of National Bureau of Statistics, and Economic and Development Department of the State Ethnic Affairs Commission. 2003. Sub-ethnic Data of 2000 National Population Census of China, vol. 1. Beijing: The Ethnic Publishing House.

Department of Population and Employment Statistics, National Bureau of Statistics, and Economic Development Division of the State Ethnic Affairs Commission. 2013. Sub-ethnic Data of 2010 Population Census of China. Beijing: The Ethnic Publishing House.

Dikötter, Frank. 1992. The Discourse of Race in Modern China. Stanford, CA: Stanford University Press.

Dreyer, June Teufel. 1976. China's Forty Millions: Minority Nationalities and National Integration in the People's Republic of China. Cambridge, MA: Harvard University Press.

Enloe, Cynthia. 1996. Religion and Ethnicity. In Ethnicity, ed. Hutchinson John and Smith Anthony, 197-202. Oxford: Oxford University Press.

Feagin Joe, R, and B Feagin Clairece. 1996. Racial and Ethnic Relations, Upper Saddle River, 5th ed. New Jersey: Prentice Hall.

Gao, Ying, and Zhang Xiulan. 2014. Analysis on the Characteristics and Changing Trends of Population Structure in Megalopolis: The Case of Beijing. Population Journal 1: 64-77.

Goldscheider, Frances K., and Goldscheider, Calvin (ed.). 1989. Ethnicity and the New Family Economy. Boulder, CO: Westview Press.

Gordon, Milton M. 1964. Assimilation in American Life. Oxford: Oxford University Press.

Guo, Zhigang, and Li Rui. 2008. Marriage Age, Number of Children Ever Born, and the Ethnic Identification of Children of Inter-ethnic Marriage: Evidence from China Population Census in 2000. Social Studies 5: 98-116. 244.

The Institute of Ethnology and Anthropology of Chinese Academy of Social Sciences, the Culture and Propaganda Department of the State Ethnic Affairs Commission (ed.). 1994. The Usage of Ethnic Languages in China. Beijing: China Tibetology Publishing House.

Jian, Zhixiang. 2004. Religious Belief and the Ethnic Boundaries. Northwestern Journal of Ethnology 2: 175-187.

Li, Xiaoxia. 2004a. Status Quo of Chinese Ethnic Intermarriage. Population Research 3: 68-75.

Li, Xiaoxia. 2004b. Discussion on the Intermarriage Ring of China. Guangxi Ethnic Studies 3: 20-27. 
Li, Xiaoxia. 2008. A Survey of Inter-Ethnic Marriages in Xinjiang. Journal of Xinjiang University (Philosophy, Humanities \& Social Sciences) 3: 80-88.

Li, Xiaoxia. 2012. Investigation on Intermarriage between Uyghur and Han in Rural areas of Southern Xinjiang. Xinjiang Social Science 4: 59-66.

Liang, Maochun. 2008. Sociological Perspective of Ethnic Relations in Dayaoshan. Beijing: Social Science Academic Press.

Liu, Zhongyi, and Zhang Li. 2015. The Study on the Trend of China Ethnic Intermarriage: Comparative Analysis Based on 'Fifth Census' and 'Sixth Census'. Guangxi Ethnic Studies 3: 61-71.

Ma, Rong. 1996. Tibet's Population and Society. Beijing: Tongxin Press.

Ma, Rong. 2000. Several Issues on Ethnic Studies. Journal of Peking University (Philosophy and Social Sciences) 4: 132-143.

Ma, Rong. 2001. Ethnic minorities' intermarriage in China. In Ethnic Development and Social Change, 161-224. Beijing: Ethnic Publishing House.

Ma, Rong. 2004. Sociology of Ethnicity. Beijing: Peking University Press.

Ma, Rong, and Naigu Pan. 1988. Han and Mongol Intermarriages in Rural Chifeng, Inner Mongolia. Journal of Peking University. Philosophy and Social Sciences 3: 76-87.

Mullaney, Thomas S. 2011. Coming to Terms with the Nation: Ethnic Classification in Modern China. Berkeley: University of Californian Press.

Simpson, George E, and J Milton Yinger. 1985. Racial and Cultural Minorities: An Analysis of Prejudice and Discrimination, 5th ed. New York: Plenum Press.

Thernstrom, Abigail, and Stephan Thernstrom (eds.). 2002. Beyond the Color Line: New Perspectives on Race and Ethnicity in America Stanford. CA: Hoover Institution Press.

Wang, Junmin. 1999. Intermarriage Research on Mongol-Manchu-Hui-Han: A Case Study of Urban Hohhot. Northwestern Journal of Ethnology 1: 157-169.

Wang, Tongling. 1934. Chinese Ethnic History Shanghai: The Culture Association.

Weber, Max. 1978. Economy and Society, vol. 1, eds. G. Roth and C. Wittich. Berkeley: University of California Press.

Xie, Yu, and Kimberly Goyette. 1997. The Racial Identification of Biracial Children with One Asian Parent: Evidence from the 1990 Census. Social Forces 76 2: 547-570.

Yan, Ruxian,(ed.). 1986. Marriage and Family of Chinese Ethnic Minorities. Beijing: China Women Publishing House.

Zhao, Jinshan, and Xu Ping. 2014. Investigation of Ethnic Cultural Identity in Guangxi Zhuang Autonomous Region. Journal of South-Central University for Nationalities 2: 55-59.

Submit your manuscript to a SpringerOpen ${ }^{\odot}$ journal and benefit from:

- Convenient online submission

- Rigorous peer review

- Open access: articles freely available online

- High visibility within the field

- Retaining the copyright to your article

Submit your next manuscript at $\gg$ springeropen.com 